\title{
COBRESAL CAMPEÓN DEL FÚTBOL CHILENO 2015. O CUANDO EL PATERNALISMO INDUSTRIAL Y LA ÉPICA DEPORTIVA SE COMBINARON EN EL NORTE DEL PAÍS.
}

\author{
Cobresal Champion of the Chilean Football League 2015. Or When Industrial
}

Paternalism and Sport Epic Were Combined in the North of the Country

\section{RODRIGO HERRERA*}

Fecha de recepción: 18 de octubre de 2017 - Fecha de aprobación: 14 de agosto de 2018

\section{Resumen}

El Salvador, campamento minero del norte de Chile, ha vivido una trayectoria delimitada por su vinculación a la lógica urbanística de las company towns y su dependencia de una industria extractiva como la del cobre. Pero en 2015 ocurrieron dos eventos que la llevaron a vivir momentos extremos: lluvias inesperadas, seguidas no muy de lejos por el título de campeón del fútbol profesional de su club, Cobresal. El siguiente artículo explora esta coyuntura, armando un relato contextualizado de la experiencia vivida por los propios futbolistas, fundiéndola con la interpretación periodística del momento a partir del cruce de los testimonios en y de la propia prensa. El resultado muestra la consolidación de un relato que resalta la gesta épica deportiva, fundiendo los valores que incubaron el logro futbolístico con aquellos que hablan de la propia vida cotidiana en el campamento y su tradición de esfuerzo por parte de los trabajadores.

Palabras clave: Paternalismo industrial; vida cotidiana; fútbol profesional

\section{Abstract}

El Salvador, a mining camp in the north of Chile, has lived a trajectory delimited by its link to the logic of the company towns and its functionality and dependence on an industry such as copper. But in 2015, two events took place that led her to experience extreme moments: unexpected rain and a professional soccer championship title. The following article explores this situation, putting together a contextualized story of the soccer's lived experience, fused crossing journalists interpretation of the moment. The result shows the consolidation of a story that highlights ths sporting event, fusing the values that incubated football achievements with those who speak of one's daily life at mining camp and its workers tradition of effort.

Keywords: Industrial paternalism; daily life; professional football *Dr. en Antropología. Académico Vicerrectoría de Vinculación con el Medio, Universidad de Concepción, Concepción, Chile.
Correo-e: rherrerao@udec.cl 


\section{Introducción}

El ejercicio que se presenta a continuación no profundiza en una problematización científica específica, ni discute una perspectiva crítica desde algún horizonte disciplinar. Es, antes bien, una recopilación de las impresiones y los sentimientos que acompañaron y dieron sentido a un acontecimiento particular. Este removió la vida cotidiana de un lugar generalmente alejado de las luces y la vorágine de la vida contemporánea, como El Salvador, en la región de Atacama, Chile. Nos referimos al título de campeón del fútbol profesional de Chile ganado por el club Cobresal, originario de la ciudad. Este hecho singular puso, por algunos días, en el centro del acontecer informativo, no solo al grupo de futbolistas que componen el club, sino también a la ciudad, sus ritmos, secretos $\mathrm{y}$ vaivenes.

Para ello, se pasa revista a diferentes medios de comunicación, en los que diversos actores vinculados dan sus impresiones acerca del acontecimiento, transformándolo, de paso, en un fenómeno social, que no será analizado in situ, ni de forma directa. La revisión del mismo se hará a través de los relatos publicados que describen -pero al mismo tiempo construyenuna situación social compuesta de contrastes, comparaciones, emociones y sentimientos que ponen sobre la mesa ciertos valores.

No se pretende en este ejercicio exponer que el fútbol actúa como reflejo de la vida social y de los valores que la sustentan. Muy por el contrario, y respetando la relativa autonomía de este tipo de fenómenos culturales señalada por autores como Alabarces (2006), se asume el mundo de los relatos surgidos en torno al fenómeno futbolístico como un espacio de expresión de principios como el esfuerzo y la cooperación, en su condición de factores de integración y demostración de fortaleza colectiva frente a las adversidades. En cierto modo, frente al sentimiento de desarraigo y dureza del entorno natural inmediato, se erigen formas cotidianas de adaptación desde el sentimiento y la valoración del estar juntos. De esta manera, el logro futbolístico obtenido permitió mostrar al resto del mundo aquellos principios de la vida social local que actúan como soportes de una estructura mayor, aunque suelen permanecer ocultos -o alejados- de los centros productores de información.

En este sentido, podemos decir que la perspectiva asumida, si bien no se alinea con una disciplina científica específica, sí recoge el valor de la actividad del etnógrafo en tanto testigo y la posibilidad de que la etnografía se proyecte como elaboradora de relatos con valor testimonial (Goffman, 1989), al recoger de la realidad todo aquello que las otras disciplinas científicas desecharon o no visualizaron. Esos vestigios de la vida social son los que el antropólogo observa y sobre los cuales reflexiona y escribe.

\section{Antecedentes: Cobresal vive en El Salvador}

El Salvador, en el norte de Chile, es un campamento minero al que solemos referirnos como ciudad, pero que para la Corporación Nacional del Cobre (CODELCO) sigue siendo una División ${ }^{1}$, es decir, una instalación de faenas y/o yacimiento donde la minera lleva a cabo operaciones de la gran minería del cobre. Este asentamiento fue construido por la Andes Mining Company en 1959, a 2.300 metros sobre el nivel del mar, en la región de Atacama, a $1.100 \mathrm{kms}$ de distancia de la capital 
del país. Su surgimiento vino a significar una alternativa laboral y residencial para una población que hasta entonces orbitaba alrededor de diversas explotaciones mineras cercanas, como Potrerillos, La Mina y Las Vegas. De ahí el nombre de El Salvador, cuenta la oralidad. Su diseño, basado en casas organizadas por sucesivos anillos concéntricos cruzados por avenidas, estuvo a cargo del arquitecto Raymond Olson, quien asumió el encargo de erigir un campamento modelo que debía incorporar los conceptos del good living, health and recreation, propios del New Deal propuesto por Estados Unidos para Latinoamérica, que incluía diversas disposiciones de carácter social para sus trabajadores-residentes, siguiendo la lógica de las company towns (Garcés, 2008)2

De alguna manera, se trata de una gran obra de ingeniería social porque, considerando su aislamiento, se diseñó para ofrecer condiciones que permitieran una simbiosis entre funcionalidad urbanística y actividad productiva, concibiéndose bajo los parámetros de la "ciudad ideal" (Baros, 2006) ${ }^{3}$. En términos urbanísticos, su construcción está hermanada con la del campamento de Cerro Sombrero, en Tierra del Fuego, Región de Magallanes, erigido por la Empresa Nacional del Petróleo (ENAP) entre los años 1958 y 1961. Ambos forman parte del ideal moderno de construcción que apuntaba a la edificación de entornos urbano que ojalá pudiesen autosustentarse y funcionar como organismos autónomos para cumplir con las condiciones de comodidad y habitabilidad proyectadas para los trabajadores industriales y sus respectivas familias (Domínguez, 2011). En esos casos, el arquitecto -entendido como un reformador social- emprende la tarea de construir enclaves urbanos con base en los ideales de la sociedad moderna, siguiendo los principios del habitar-trabajar-recrearse-circular. La arquitectura adopta así un carácter ideológico que la convierte en una disciplina al servicio del progreso y la modernización de la sociedad.

Desde un punto de vista más sociohistórico, podría señalarse que su historia oficial ha estado ligada a los vaivenes de la minería del cobre en el centro y norte de Chile y está emparentada con proyectos productivos asociados a soluciones habitacionales, como Sewell (1906), Chuquicamata (1915), Potrerillos (1920), entre otros. Todas estas son "ciudades del cobre", definición de Garcés (2003) para señalar aquellos asentamientos emprendidos por empresas internacionales para atender funciones productivas, residenciales y de equipamiento bajo el control exclusivo de la industria. Su propósito era alcanzar resultados de eficiente producción a partir de una autosuficiencia que posibilitara el control del conjunto desde un sistema empresarial y jurídico. En este contexto, El Salvador vendría siendo la última ciudad del cobre que mantiene operaciones extractivas tradicionales.

Sin embargo, también puede leerse su historia a partir del esfuerzo de sus trabajadores, mismo que ha sido recompensado, en el decir del relato que la empresa construye, con ser testigos directos del progreso ${ }^{4}$. Si lo vemos desde el punto de vista de la organización obrera, como parte de una trayectoria de reivindicaciones comunes a los trabajadores de la minería del cobre, con su despliegue continuo de manifestaciones y luchas, El Salvador ocuparía un lugar de privilegio, como "el campamento minero más combativo" en su corta historia (Cerda, 2016). 


\section{El verde de El Salvador es de Cobresal}

A partir de este pasado, su presente y futuro parecen ir plegándose en un extraño reflejo que combina esfuerzo con nostalgia, templanza con pesimismo, sacrificios con opulencias pasajeras. Una buena síntesis de esta extraña combinación va sugerida en uno de los comentarios más recurrentes que provienen desde su interior: "la mina lleva cuarenta años cerrando, y ahí sigue..." (Luis Guerra, socio fundador de Cobresal) ${ }^{5}$. Esa dinámica es la que ha permitido, sin embargo, el surgimiento de ciertos recorridos y anhelos comunes entre sus habitantes, que sin bien están mayoritariamente ligados al trabajo en el mineral, también se adentran por otros derroteros de la vida cotidiana en la ciudad-campamento.

Más allá de lo relativo a la organización del trabajo, los turnos y la producción del cobre, y del movimiento obrero, con sus luchas y reivindicaciones, se han formado espacios sociales en apariencia menos trascendentales que los mencionados, pero que también llenan el tiempo con emociones y sensaciones novedosas y crean nuevos nichos desde donde la colectividad se siente representada. En ellos surgen temas de conversación, se promueven nuevos vínculos y se transforman las rutinas para escapar de la monotonía abrumante del paisaje siempre invariable que ofrecen el desierto y la distancia. Como parte de ese cúmulo de cosas poco importantes que acaban por serlo a fuerza de volverse parte de la vida de quienes habitan El Salvador, tenemos el equipo de fútbol profesional Cobresal, fundado en el año 1979. Un equipo de fútbol; sencillamente, es cierto, pero quizá, además, "una excusa para que sus habitantes tuvieran algo que hacer".
La historia del club no es demasiado larga. El dato oficial habla de la conformación de la comisión "Cobresal en ascenso" un 26 de abril de 1979 , compuesta por gerentes y profesionales de la empresa minera que se reunían tradicionalmente en el Club Pampa o Pampa Club. Y lo que en un principio emergió como un anhelo, el 5 de mayo cobró impulso, después de que el gerente general de la minera diera el sí para un aporte económico desde la empresa, detalle imprescindible para darle viabilidad al proyecto. De ahí saltamos a su primer partido en el profesionalismo, un 20 de abril de 1980, momento en que inicia su participación en la segunda división del fútbol chileno con la visita al equipo de Regional Atacama, oriundo de Copiapó, capital de la región homónima.

Pero llegar a jugar aquel partido no fue fácil. Según la reglamentación de la época, para acceder al profesionalismo y ser parte de la Asociación Nacional de Fútbol Profesional (ANFP), se debía tener una afiliación previa en la organización de la Asociación Nacional de Fútbol Amateur (ANFA), a través de algún club miembro. Ante la necesidad de este requisito, el Club Deportivo Hospital de El Salvador le ofreció afiliarse. Con ello se pudo levantar la postulación para ingresar al profesionalismo:

[...] entrar a $2^{\text {a }}$ División no era un trámite sencillo. En 1979 Copiapó también quería ingresar y su intendente era un coronel, así que tuvimos que ir hablar a la DIGEDER en Santiago, en el Ministerio de Defensa [...] Estaba el general Nilo Floody y le dijimos que era mejor que los trabajadores se concentraran en el fútbol en lugar de la política, y como estábamos en dictadura, eso lo convenció. Y como Copiapó también quería entrar, dijo "¡Ya, juegan los dos!" (Bruno Behn, socio fundador de Cobresal) ${ }^{7}$. 
Se necesitaba una excusa, la de que los trabajadores tuvieran algo que hacer, además de trabajar en la mina u organizarse por alguna reivindicación colectiva.

El disciplinamiento social propio del paternalismo exige adhesión, consenso, aceptación $y$, también, participación, por lo que remite a un tema mucho más profundo que la mera obediencia ciega o anclada en bases represivas (Mantecón, 2010). Por lo mismo, es interesante la mirada sobre el paternalismo industrial en cuanto conjunto de mecanismos de control destinados a cubrir una serie de necesidades sociales de los trabajadores, a saber, vivienda, salud, educación de los infantes, entretención y algunos aspectos de sociabilidad, utilizados por las empresas para adaptar a sus operarios a las demandas al interior de las villas o poblaciones diseñadas para su permanencia en las cercanías de las labores fabriles o extractivas, asegurando de esta manera la existencia de mano de obra segura y altamente adiestrada (Godoy, 2015).

Pero si bien el urbanismo es un claro aliado para lograr disciplinamiento a través de la distribución espacial que controla el diseño, la asignación y el uso del espacio construido, también el dominio sobre el ocio constituye una herramienta que permite introducirse en los tiempos del no-trabajo (Sierra Álvarez, 1986). Con ello se pretende la construcción de una sociabilidad obrera alejada de los vicios y la participación política, pero no siguiendo un orden represivo, sino mostrando un rostro social que permite introducir mejoras en la calidad de vida de los trabajadores y sus familias.

Sabemos, no obstante, que nunca se ha llegado a una sociedad completamente disciplinada, reducida a una obediencia acrítica y que responda de forma automática a los valores proyectados desde arriba. Tampoco desde abajo ha sido todo consenso, sino, más bien, presiones, resistencias y valores variables, o capacidad creativa o reglas de convivencia gestadas desde el mismo lugar. Por ello, quizá, en este caso específico, además de la planificación controlada por alguna gerencia, también estaba el fuerte deseo de los trabajadores por contar con un club de fútbol profesional.

Desde la percepción del proceso de fundación del club dentro del derrotero de la dinámica paternalista, este se insertaría en una línea marcada por la continua preocupación de la minera por ofrecer infraestructura de bienestar a sus empleados. A la Escuela Americana y la Escuela №1 (o Chilena) y el hospital, inaugurados en los primeros años de la década de 1960 , los clubes sociales de finales de la misma década, el cine Inca de los setenta, le siguió el club de fútbol en los años ochenta, casi en sintonía con una cadena lógica de circunstancias que fueron llenando el paisaje del desierto. Puede resultar, entonces, expresión también de este paternalismo informal señalado por algunos como una forma de encubrir, con sensibilidad social, el afán de control total que busca incidir en una mejor productividad (Godoy, 2015).

Pero esto deja fuera otro conjunto de factores incidentes en la fundación del club. La larga existencia de una liga de fútbol amateur de diez equipos permanente desde la fundación del campamento, un combinado minero que de vez en cuando jugaba partidos con equipos profesionales, el éxito que comenzó a tener Cobreloa -equipo también minero fundado en 1977 para representar a Chuquicamata y Calama, otros enclaves cupríferos fundamentales del norte chileno-, fueron también dando 
fuerza a que se diera la posibilidad de cumplir lo que parecía una quimera para los trabajadores: llevar el fútbol profesional a un campamento minero aislado, remoto y casi insignificante en el mapa nacional.

O sea, podría pensarse que Cobresal responde a un anhelo fuertemente deseado "desde abajo", pero que lógicamente tuvo que ser gestionado "desde arriba". Ninguno de los dos ámbitos podía pasarse del otro, sino que había una fuerte interdependencia. De hecho, los testimonios de la época así lo indican. Una vez iniciado el proceso de conformación del club, el semanario Andino empezó la fase de captación de socios con textos que llamaban al conjunto de la población a enfrentar la responsabilidad de tener un equipo de fútbol profesional, coyuntura para la cual sería fundamental la unión de todos: trabajadores y sus familias; autoridades, civiles y militares; comerciantes, la empresa y hasta contratistas (Cerda, 2016). Todos en la tarea, disciplinadamente: trabajadores y jefes actuando con base en los parámetros de la regulación social y en función de un objetivo común.

Ahora bien, en paralelo a todo este trabajo político-administrativo siempre corrió el tema del estadio. $Y$ aquí otra vez su cristalización aporta datos que demuestran cómo la realidad siempre se está superando a sí misma: formalmente, el $1^{\circ}$ de junio de 1980 se inaugura el estadio El Cobre, un proyecto en el que muchos no creyeron. Se tuvo que acarrear tierra desde Copiapó, ciudad cabecera regional, hasta "arriba". En un campamento donde su máximo de población era de 15.000 habitantes durante los años ochenta, donde su promedio no ha superado los 10.000 y donde actualmente viven aproximadamente unos 7.000 a 8.000 , y con una capacidad inicial para 8.000 personas, el estadio era ya grande de acuerdo con esas magnitudes de población. Dicho en términos simples, para que se llenara el estadio, debía acudir a él más de la mitad de sus habitantes. De hecho, al partido inaugural asistieron 7.696 personas, que según referencias de la época, abarrotaron el coliseo. Lo más curioso es que, posteriormente, para cumplir con los requisitos para su participación en la Copa Libertadores de América, en 1986 el estadio se amplió para una capacidad de 20.700 espectadores, más que el total de habitantes de campamento. Así se conformó "el estadio más grande del mundo".

Pero sería mezquino quedarse solo con los antecedentes numéricos al respecto. El hito de su construcción, y no sólo de su inauguración, pone de relieve toda una declaración de principios en relación con la vida en el campamento: "El verde de la camiseta es por el pasto. El césped en el desierto revolucionó todo. Una maravilla" (Ariel López, socio fundador de Cobresal)8. "¿Tú has visto dónde está el estadio?, ¿has visto lo que hay alrededor?... Y mira lo que conseguimos. Ese pasto es la octava maravilla mundial" (Luis Guerra, socio fundador de Cobresal) ${ }^{9}$. Un dato viene a reafirmar lo dicho: el mayor espacio verde de El Salvador es el campo de pasto natural del estadio El Cobre, lugar donde juega Cobresal. El resto es desierto, cemento y unos cuantos árboles, de preferencia en el barrio americano, donde se ubican las casas de los gerentes. Otro dato que reafirma estas convicciones: desde su inauguración, el césped no ha sido nunca resembrado y ha estado cuidado, hasta el día de hoy, por el mismo canchero: Ibar Rivera, "El Camello". Todo esto reafirma lo dicho: el verde de la camiseta es un homenaje, un tributo que se le rinde al pasto, por su indudable escasez y el esfuerzo que implica su existencia en ese entorno. 


\section{"Lo que no mata fortalece". Nietzche en El Salvador}

El verde de la camiseta, la tradicional presencia de hinchas del club en diferentes estadios alrededor del país cuando el equipo juega de visita -aunque sea solo uno- o las propias dimensiones del estadio El Cobre permiten pensar que los ámbitos de influencia del equipo de fútbol y todo lo que él genera superan en mucho aquella proyección inicial planificada al momento de su fundación. Podríamos quedarnos únicamente con resaltar su condición de refugio para el desahogo y conducción de emociones o su fuerza distractiva como potencial canalizador de energías. Pero también puede que estas visiones, con todo lo certeras que puedan ser, no logran tampoco completar el círculo y agotar su profundidad. Porque una vez más, el fútbol demuestra ser más complejo de lo que aparentan quienes lo comentan. Sobre todo cuando se mezcla con lógicas de paternalismo empresarial en zonas remotas de un país aún más remoto. Es entonces cuando su condición de evento social aglutinante y, en parte, emotivo, nos conduce por las formas en que la realidad muestra su rostro más complejamente irreflexivo, pero contradictoriamente rutinario, en tanto acumulación ritual de expresiones claramente cohesionantes, a pesar de parecer profundamente incoherentes. El fútbol separa, pero también junta. Las prácticas paternalistas regulan, pero también a veces generan, imprevistos que no estaban en los cálculos de nadie.

Sin duda, es en este entrecruce de caminos donde observamos una vez más cómo el mundo del fútbol excede su ámbito tradicionalmente reservado a conversaciones relativas al desempeño deportivo, ubicación en la tabla, rendimiento de tal o cual jugador o a los vaivenes de quienes son sus actores privilegiados: futbolistas y entrenadores. El evento fútbol se contextualiza en un lugar, tiempo y espacios singulares, "hablando" por la sociedad, mostrando -en tanto fenómeno social total (Mauss, 1979)otras caras de las bases que la constituyen, dando fe de las innumerables formas en que la cotidianeidad se construye y reproduce de manera compleja en el mundo contemporáneo. $Y$ en el caso que nos congrega, develando propiedades, vinculaciones, necesidades y anhelos implícitos o explícitos de quienes habitan El Salvador.

Ello se observó cuando aquel equipo históricamente acostumbrado a la medianía de la tabla, sin grandes campañas, aislado, comienza a encumbrarse en 2015 hasta llegar a posiciones de avanzada, sin que nadie le pusiera demasiada atención en un primer momento. Aunque lo de después pareció inevitable. Porque justo en aquellos trances en que el equipo subía su autoestima a punta de resultados deportivos se produjo la gran catástrofe: lo que había empezado como una anécdota y casi un jolgorio para los habitantes de zonas donde si cae lluvia ya es noticia, con el paso de las horas acabó transformándose en una tragedia de proporciones, por la cantidad de las precitaciones, que acarreó crecidas de ríos, deslizamientos de tierra, agua en las quebradas y todo lo que deriva de un fenómeno tan inesperado en el norte de Chile, en que los ríos con agua pueden contarse con los dedos de una mano. Este evento, que acabó siendo parte sustantiva de la construcción de la épica cobresalina, obligó coyunturalmente al equipo de fútbol a abandonar el campamento de El Salvador al final del mes de marzo, para ir a asentarse y entrenar en Santiago, dadas las dificultades que aún existían en una zona decretada como "de 
catástrofe" y los problemas de abastecimiento de la población en general. "No teníamos agua y las condiciones no eran las mejores para preparar el partido con Colo Colo que será muy importante para nosotros" (Reportaje Emol Deportes) ${ }^{10}$.

En ese trance, los jugadores pasaron a representar a un grupo de luchadores tenaces que hacían frente a todas las adversidades que surgían en el largo camino a la gloria. Para ello hicieron lo que su condición ameritaba: optaron por reforzar sus lazos, hacerse fuertes a través del colectivo y proponerse como objetivo final darle una alegría a quienes más habían perdido con la tragedia de la naturaleza. 'No podíamos suspender el partido. Era la única forma de decir que éramos capaces de salir adelante, a pesar de todo lo que habíamos pasado. Jugamos pensando en darle una alegría al norte. Más que los tres puntos, lo que importaba era darle fuerza a la gente de Copiapó y Atacama. Queríamos demostrar que nos podíamos levantar, tal como ellos" (Nicolás Peric, arquero y uno de los voceros del equipo). Había que "lograr algo, Atacama necesitaba de nosotros" (ídem).

Por primera vez en muchos años, los jugadores pasaban a tener nombre, apellido y recorrido y su entrenador se había transformado en todo un estratega, y más que nada en un psicólogo. La ciudad-campamento comenzaba a tener visibilidad más allá de su condición de ejemplo de aislamiento. $Y$ extrañamente, pasó que, de pronto, Cobresal empezó a ganar simpatías y a generar adhesiones en la gente. También El Salvador, ese lugar que "a primera vista, intimida e impacta" (Dalcio Giovagnoli, director técnico del Club Cobresal) ${ }^{11}$.
Más aún, hasta el propio aislamiento crónico e inevitable del campamento fue reintrepretado por los propios jugadores, convertidos ahora en actores principales de una trama que conllevaba una verdadera montaña rusa de emociones. Los futbolistas y sus familias, al desplazarse a la capital para aislarse de las consecuencias del temporal, resintieron sentimientos de afinidad. 'Nos sentíamos abandonando el barco. Cobresal es un equipo chiquitito, donde nos conocemos todos. Nos sentíamos parte de la catástrofe y queríamos ayudar" (Johan Fuentes, jugador del club Cobresal)12. "Yo creo que igual se echan de menos las juntas en El Salvador, el jugar póker y esas cosas, porque hace más fuerte al grupo" (Nelson Sepúlveda, jugador del club Cobresal ${ }^{13}$. "En los entrenamientos se sigue dando lo mismo, nos quedamos hasta más tarde, peluseamos y nos reímos. Esa es la esencia que tenemos. Quedan pocas fechas y tenemos que estar con los dientes apretados, no hay tiempo para ponerse melancólico" (Víctor Hugo Sarabia, jugador del club Cobresal) ${ }^{14}$. "A pesar de lo difícil que es estar allá, paradójicamente debimos luchar contra el desarraigo, porque muchos de los jugadores tuvieron que sacar a sus hijos del colegio. No fue solo una cuestión deportiva. Pero eso parece que nos fortaleció. A partir de ahí comenzamos todos los entrenamientos gritando: lo que no mata, fortalece" (Dalcio Giovagnoli, director técnico del club Cobresal) ${ }^{15}$. Hasta en el diario El País de España el equipo fue comparado con el "ave fénix que resurge de las cenizas"16.

Ya nada ni nadie podía frenar el proceso que crecía. Y dada la necesidad de construir un relato que acogiera méritos para ser campeón (nadie puede salir campeón sin méritos, estos pueden ser discutibles, invisibilizados por los que no ganan, pero deben existir), el recurso a 
la mano fueron las analogías. Eso sí, en este caso, la historia de David contra Goliat parecía aumentada, porque al lado de esos Goliats que eran los poderosos del fútbol chileno, ricos, acostumbrados a ganar, David se veía aún más pobre y golpeado, aún más chico, mucho más precario, dado su particular momento. Y más apego generó aquel relato cuando comenzaron a emerger las cualidades de aquel David que, condenado antes al anonimato, sabía de sobra lo que era la adversidad y había desarrollado un conjunto de "valores" que el resto de la sociedad -especialmente el mundo de los Goliats ricos y poderosos-, comenzaba, primero, a descubrir y, después, a mirar con simpatía y quizá hasta con envidia.

Ahora el candidato estaba donde estaba no solo con base en el "esfuerzo" y el "sacrificio" de un grupo anónimo de personas compuesto por jugadores, cuerpo técnico, demás oficiantes del club deportivo e incluso todos los habitantes del campamento-ciudad. También eran parte de David las respectivas familias que se habían sacrificado trasladándose al campamento, además de los hinchas y socios que siempre dicen presente en los estadios. Todo este conjunto, a los ojos de los afuerinos, componía una comunidad, se puede decir que más por la fuerza que por la razón, pero en la que la mancomunión entre todos y cada uno comenzaba a ser mencionada, reconocida. A lo que se enfrentaba el resto de los equipos de ahí en más era a una familia, la gran familia salvadoreña. "Estamos obligados a tener buena onda en el plantel, es lo primordial. No sé si se darían buenas campañas si no existiera un buen grupo acá en Cobresal. El pueblo es demasiado chico, no te puedes pelear con nadie, ni siquiera en tu casa" (Víctor Hugo Sarabia, jugador del club Cobresal) ${ }^{17}$. "Esto más que un equipo es una familia. Y lo que se está logrando es el resultado del trabajo, porque no tenemos aquí ninguna figura" (kinesiólogo del club Cobresal) ${ }^{18}$.

Este espíritu de comunidad se convirtió en un catalizador emocional que, sin duda, permite entender y explicar muchas cosas. Tanto para los afuerinos que llegaban a tratar de entender cómo David había derribado a tantos Goliats, como también para los propios Davids, que de pronto necesitaban inventar explicaciones para entender lo que estaba pasando. Fue como si, frente a la llegada de observadores externos -medios de comunicación provenientes principalmente de Santiago-, la vida cotidiana de El Salvador, recurrentemente sacrificada, regular en su condición disciplinar, de pronto adquiría nuevas cualidades y connotaciones especiales. La monotonía se transformaba en fraternidad, la rutina en virtud, la escasez en abundancia. A falta de malls en el campamento, bueno era el póker en casa de Paco Sánchez, lateral derecho del equipo, o las películas con asado incluido en la casa del Nico Peric, el arquero. La plaza se vuelve un lugar de encuentro porque hay pocos lugares alternativos para estar en la tarde en familia y allí llegan todos. El Club Social Rayuela es un bastión para las necesarias "picadas" de comida que la mayoría degusta en algún momento de la semana.

El Salvador, lugar difícil y áspero, de pronto mostraba un rostro amable. "Creo que no existen equipos que logren grandes objetivos sin tener un grupo unido y un ambiente acogedor. El Salvador, por sus características, te da eso. En una ciudad más grande, vas del entrenamiento a casa y el contacto que puedes tener fuera es poco o nada. Acá estamos todos en la misma" (Federico Martorell, jugador del club Cobresal) ${ }^{19}$. "Ahí el grupo se repliega para 
mal o se fortalece, y aquí está sucediendo lo segundo" (Dalcio Giovagnoli, director técnico del club Cobresal) ${ }^{20}$.

Finalmente, el 26 de abril de 2015 por la tarde, la cancha de El Cobre, el espacio verde más grande en cientos de kilómetros a la redonda, albergaba solo emoción y lágrimas. $Y$ en el festejo que pudo verse ahí, se volvió a apreciar que los astros se congeniaban con la leyenda de David. La celebración estuvo marcada por la sencillez. En un rincón de la cancha, sin escenario ni cotillón de por medio, la copa, puesta en una mesa improvisada, fue entregada al capitán del equipo, quien la recibió junto al grupo de jugadores y todo el montón de familiares que a esas alturas ya había ingresado al campo de juego para ser parte -aunque en la práctica, eran parte hace rato ya- de la fiesta. Posteriormente, la misma Asociación Nacional de Fútbol Profesional (ANFP) se vio obligada a emitir un comunicado exponiendo las razones de la austeridad de la ceremonia de entrega del trofeo al campeón, aduciendo motivos externos ligados a la prohibición de trasladar material pesado por carreteras castigadas por la catástrofe, lo que había impedido trasladar escenarios y otros. Pero eso fue días después, cuando a nadie le importaba ya y todas las celebraciones habían corrido por el carril de la leyenda de David y la sencillez con que asumía su logro.

Revisando el tema a posteriori, podríamos decir que ese día todo fue a pedir de boca, no solo para el puñado de jugadores, sino para la gran familia salvadoreña. Justo en el retorno del equipo a su cancha en El Cobre, y a falta de una fecha más por jugarse, podía salir campeón, si es que se daban otros resultados. Que se dieron. Eso permitió celebrar en casa, con la gente de casa. Durante el partido, que se jugaba contra
Barnechea, equipo ya descendido a la segunda división, podía verse por la pantalla de la televisión, detrás de uno de los arcos, un lienzo grande que decía: "El Salvador se levanta con la fuerza de su gente". Casi un mes después de las lluvias y los aluviones que sacudieron a la zona, después de que el equipo de fútbol tuviera que irse a entrenar a Santiago porque en el campamento no había agua y después de haber salido del ostracismo futbolero con su triunfo sobre Colo Colo en su propia cancha, Cobresal no podía hacer otra cosa que sufrir otro poco para alcanzar lo deseado. Remontó un 2 a 0 en contra, esperó un milagro que sí ocurrió en otras canchas y le dio una alegría a todos los Davids repartidos por el territorio, que a esa altura ya eran muchos y que cada vez se identificaban más con el David minero.

El festejo inmediatamente posterior fue en el lugar de concentración habitual, el hotel Camino del Inca de la misma ciudad, en una cena que, imponderablemente, todos los medios de comunicación no titubearon en llamar "íntima", "familiar". Más de alguno de los jugadores asistentes de seguro llegó caminando al lugar. $Y$ no hubo grandes alborotos a la hora del ingreso de los jugadores, siempre hubo el tiempo para los autógrafos de rigor, los saludos y las fotos con los hinchas. Había gente, pero obviamente no podía haber demasiada: el pueblo se está quedando vacío.

Al otro día, el ave fénix y los Davids despertaron campeones y no se les ocurrió nada mejor que celebrarlo en compañía. El plantel completo en un bus, seguido por una caravana de cerca de cuarenta autos desde El Salvador, "bajó" a Diego de Almagro, el pueblo más cercano a El Salvador $(58 \mathrm{~km})$, uno de los más afectados por los aluviones del temporal del mes anterior. 
Sintomático el relato del arribo, según lo detalla el registro de la prensa local ${ }^{21}$ : llegaron hasta una céntrica estación de gasolina del pueblo, bajaron los jugadores, la copa y todos al gimnasio del colegio Aliro Lamas a un evento público donde los campeones compartieron con niños y adultos de la localidad. Aparecieron los cobresalinos anónimos -jubilados, ex mineros, jóvenes que nacieron siendo socios del club por el fanatismo de sus padres, ex jugadores incluso-y los no tan anónimos -Iván Zamorano, ídolo nacional fue el "padrino" de la ceremonia, debido a su pasado juvenil en el club.

Si el día lunes las páginas deportivas de la prensa nacional mostraban las imágenes de la euforia, el llanto y la felicidad en aquel pasto en medio del desierto, las del día martes eran más inquietantes: jugadores y copas se paseaban entremedio de ruinas de lo que fueron casas y calles, acompañados por pequeñas multitudes que agitaban banderas "albiverdenaranjas", todos felicitándose y aprovechando de descargar tanta emoción contenida. "Estamos muy agradecidos de que se hayan acordado de nosotros. Ellos son los campeones, pero tienen la humildad de venir a compartir con nosotros acá. Por eso vinimos, para agradecerles y sacarnos unas fotitos con los jugadores" (reportaje diario La Tercera) era el sentir de los habitantes del pueblo. "Dejamos de ser futbolistas una vez que cumplimos el objetivo, por lo que venimos aquí como personas, y en ese sentido es muy emocionante para mí, como padre, ver a todos estos niños sonriendo" (reportaje diario La Tercera) fue la síntesis de lo expresado por los jugadores ${ }^{22}$. La emoción seguía siendo pieza fundamental de la trama.

\section{El retorno de la normalidad: el relato épico llega a su fin}

El día jueves 30 de mayo las noticias deportivas dejaron de interesarse en Cobresal, el hace unos días David del desierto. O también puede pensarse que volvieron a ocuparse de lo nunca dejó de ser importante, solo que se había vivido un pequeño paréntesis en el acontecer de los equipos grandes y los resultados del fútbol internacional, con especial énfasis en las estrellas del balompié chileno. También empezó la cuenta regresiva para la Copa América a realizarse próximamente en el país. De vez en cuando ciertas viñetas informaban del mineral al mundo, aunque eran noticias que cabían dentro de lo esperable en la post-épica: tal jugador deja el club porque le ofrecieron algo mejor y, más importante aún, en otra ciudad; ciertas voces directivas hablan del orden financiero ejemplar del club que no iba a hipotecarse para realizar contrataciones fastuosas, que eso significaría la ruina el día de mañana; rumores del futuro del equipo, que de pronto se había vuelto rendidor en lo deportivo, pero que nunca sería rentable económicamente.

Para la experiencia nortina, el acontecimiento se asemejó a la aparición del "desierto florido": un evento intenso, pero pasajero, al final del cual no es posible avizorar lo que hubo o sucedió porque no quedan huellas ni testimonios materiales. Solo queda, para intentar explicarlo, la memoria de quienes vivieron el acontecimiento, que seguramente querrán contarlo a quienes no pudieron estar allí, aunque nunca será lo mismo. A ver si así se genera alguna adhesión, a ver si así crece la hinchada y se hace más fiel el apego al escudo. 
La normalidad volvió a quedar instalada. $\mathrm{Y}$, con ella, la vuelta a la vida rutinaria, en este caso marcada por la constante amenaza del fin de la explotación minera, cierre del campamento, fin del club de fútbol. Porque, tal como lo señala Garcés (2003), no hay que olvidar que al establecerse los campamentos mineros que explotan recursos no renovables, las empresas establecen sus horizontes temporal y productivo a partir del volumen y la ley de los yacimientos y las estrategias industriales de explotación. O sea, sus parámetros están más allá de los acontecimientos que dan o han dado vida a sus habitantes. Tal como aconteció con Sewell, Potrerillos o Chuquicamata, o el conjunto de oficinas salitreras, puede llegar el día en que por allí solo lleguen turistas o el silencio del viento cordillerano. La épica, asociada a un grupo de individuos que de pronto instalaron el campamento minero en el mapa nacional, no será más que un recuerdo, quizá incluso desterritorializado. Y la cancha, aquella que ha sido sembrada solo una vez desde su inaugura- ción, se convertirá en un lugar mítico por el que alguna vez pasaron los campeones.

Por defecto, queda pendiente saber si aquellos valores y principios destacados en su momento por los medios -siguiendo las señas de quienes fueron protagonistas del sucesoseguirán circulando, densificando la vida local y proponiendo parámetros a través de los cuales interpretar la vida en común. Por mientras, solo nos queda la sensación de que los relatos que los resaltaban cumplieron su función del momento: explicaron lo extra-ordinario y, con ello, permitieron seguir con la vida cotidiana.

P.D.: El día 13 de mayo de 2017, en un partido frente a Santiago Wanderers en Valparaíso, Cobresal selló finalmente su descenso a la $1^{\text {a }}$ división $\mathrm{B}$ del fútbol profesional. Los miedos y temores de un cierre de la mina y del fin del equipo de fútbol vuelven a acechar el horizonte de los habitantes de la ciudad-campamento. 


\section{Notas}

${ }^{1}$ Ver: www.codelco.cl

${ }^{2}$ El modelo de las company towns buscaba, precisamente, conformar asentamientos que constituyeran una solución desarrollada para conseguir máxima concentración de capital y mano de obra, perfeccionando el nuevo asentamiento industrial con base en la estructuración de una estricta jerarquía social, la dotación de bienestar para cada uno de los habitantes-obreros y el control del comportamiento de cada individuo, desde la figura paternal de la empresa (Garcés, 2008, p. 30).

${ }^{3}$ Para mayor profundización en el tema, ver Baros (2006).

${ }^{4}$ Ver: http://www.codelco.cl//.

También: http://www.revistatierracultah.cl/

${ }^{5}$ Entrevista a Luis Guerra, socio fundador de Cobresal, La Tercera, 7 de marzo de 2015. Recuperado de: http://www.latercera.com/noticia/ deportes/2015/03/656-619669-9-cobresal-un-milagro-en-el-desierto. shtml. Consultado el $1^{\circ}$ de junio de 2016.

${ }^{6}$ Frase incluida en el documental El milagro de Cobresal, producido y emitido por la cadena internacional de deportes ESPN el 22 de octubre de 2016 en homenaje al campeonato obtenido el año 2015.

${ }^{7}$ Entrevista a Bruno Behn, uno de los fundadores del club profesional, El Mercurio, 27 de abril de 2015.

${ }^{8}$ Entrevista a Ariel López, fundador y socio № 4 . Recuperado en: http://www.economiaynegocios.cl/noticias/noticias. asp?id=141291. Consultado el 7 de junio de 2016.

${ }^{9}$ Entrevista a Luis Guerra, socio fundador de Cobresal. En: http:// www.latercera.com/noticia/deportes/2015/03/656-619669-9-cobresalun-milagro-en-el-desierto.shtml

${ }^{10}$ Emol, 1 de abril 2015. Recuperado de: http://www.emol.com/ noticias/deportes/2015/04/01/710860. Consultado el 7 de junio de 2016.

11 Recuperado de: http://www.latercera.com/noticia/ deportes/2015/03/656-619669-9-cobresal-un-milagro-en-el-desierto.

\section{Referencias bibliográficas}

Alabarces, P. (2006). Fútbol y patria: el fútbol y las narrativas de la nación en la Argentina. Buenos Aires: Prometeo Libros.

Baros, C. (2006). Potrerillos y El Salvador. Una historia de pioneros. Santiago: Corporación Nacional del Cobre de Chile.

Cerda, R. (2016). Gol en el campo, paz en la tierra. Santiago: Sartaña.

Domínguez, P. (2011). Cerro Sombrero. Arquitectura moderna en Tierra del Fuego. Santiago: Fondo de Fomento a la Lectura y al Libro, Consejo Nacional de la Cultura y las Artes.

Garcés, E. (2003). Las ciudades del cobre. Del campamento de montaña al hotel minero como variación de la company town. Eure, XXIX(88), 131-148.

(2008). Las ciudades del cobre. Santiago: Universidad shtml. Consultado el $1^{\circ}$ de junio de 2016.

${ }^{12}$ Entrevista a Johan Fuentes. Recuperado: http://www.quepasa. cl/articulo/actualidad/2015/04/1-16799-9-el-equipo-que-no-sabia-sercampeon.shtml/. Consultado el $1 \stackrel{\circ}{\circ}$ de junio de 2016.

${ }^{13}$ Entrevista a Nelson Sepúlveda. Recuperado de: http://www.lun. com/LunMobilelphone//Pages/NewsDetailMobile.aspx?dt=2015-0417\&Paginald $=52 \&$ Supplementld $=0$ \&bodyid $=0 \& \mid s N P H R=0$. Consultado el 7 de junio de 2016.

${ }^{14}$ Entrevista a V. H. Sarabia. Recuperado de: http://www.lun.com/ LunMobilelphone//Pages/NewsDetailMobile.aspx?dt=2015-04-17\&Pa ginald $=52 \&$ Supplementld $=0$ \&bodyid $=0 \& \mid s N P H R=0$

${ }^{15}$ Entrevista a Dalcio Giovagnoli. En: http:/www.quepasa.cl/articulo/ actualidad/2015/04/1-16799-9-el-equipo-que-no-sabia-ser-campeon. shtml/. Consultado el 7 de junio de 2016.

${ }^{16}$ Recuperado de: http://deportes.elpais.com/deportes/2015/04/25/ actualidad/1429990746_938429.html. Consultado el 1ํ de junio de 2016.

${ }^{17}$ Entrevista a V. H. Sarabia (ídem).

${ }^{18}$ Reportaje La Tercera. Recuperado de: http://www.latercera.com/ noticia/deportes/2015/03/656-619669-9-cobresal-un-milagro-en-eldesierto.shtml. Consultado el $1^{\circ}$ de junio de 2016.

${ }^{19}$ Entrevista a Federico Martorell. En: http://www.latercera.com/ noticia/deportes/2015/03/656-619669-9-cobresal-un-milagro-en-eldesierto.shtml. Consultado el 1 ㅇ de junio de 2016.

${ }^{20}$ Entrevista a Dalcio Giovagnoli (ídem).

${ }^{21}$ Ver: https://www.soychile.cl/Copiapo/Deportes/2015/04/27/ 318773/El-campeon-Cobresal-celebra-el-titulo-con-losdamnificados.aspx

${ }^{22}$ Reportaje La Tercera. Recuperado de: http://www.latercera.com/ noticia/deportes/2015/04/656-627361-9-los-festejos-de-cobresal-yel-titulo-de-toda-una-region.shtml. Consultado el $1^{1}$ de junio de 2016.

Católica de Chile.

Godoy, M. (2015). Las casas de la empresa: paternalismo industrial y construcción de espacio urbano en Chile. Lota 19001950. Universum, 30(1), 115-136.

Goffman, E. (1989). On Fieldwork. Journal of Contemporary Ethnography, (18), 123. Recuperado de: http://jce.sagepub.com

Mantecón, T. (2010). Formas de disciplinamiento social. Perspectivas históricas. Revista de Historia Social y de las Mentalidades, 14(2), 263-295.

Mauss, M. (1979). Sociología y antropología. Madrid: Tecnos.

Sierra Álvarez, J. (1986). De las utopías socialistas a las utopías patronales: para una genealogía de las disciplinas industriales paternalistas. REIS, (26/28), 29-44. 